\title{
COOPETITION (CONTEMPORANEOUS COOPERATION AND COMPETITION) AMONG NONPROFIT ARTS ORGANIZATIONS
}

\author{
Theresa A. Kirchner, Hampton University, U.S.A. \\ John B. Ford, Old Dominion University, U.S.A. \\ Edward P. Markowski, Old Dominion University, U.S.A.
}

\begin{abstract}
Coopetition (cooperation among organizations and individuals which may, in other contexts, view each other as competitors) is a concept that suggests that organizations with mutual interests can cooperate profitably at one level while competing at another. Ray Noorda, CEO of Novell, coined the term and proposed that often, in order to achieve strategic growth in an organization or industry, "You have to cooperate and compete at the same time." Coopetition is viewed as an important research area in marketing strategy because of its potential to improve profitability and competitive advantage. This study broadens research on coopetition to an arena in which it has not yet been formally studied and quantitatively assessed - the nonprofit arts subsector, assessing its manifestation in that environment with both qualitative and quantitative studies.
\end{abstract}

Academic literature on the concept of cooperation between competitors has its roots in game theory research dating from the 1940s and the work of Hamel et al. (1989). Brandenberger and Nalebuff formalized the idea of coopetition as a strategic management/marketing concept in their 1996 best-selling book. In 1999, Sheth and Sisodia, Varadarajan and Jayachandran, and Day and Montgomery called, in separate articles, for more research on the topic. However, over a dozen years later, relatively little academic work has addressed the topic. Research on coopetition during that period has focused primarily in the areas of information technology and industrial network organizations. This study answers the call for additional research on the concept in a very different arena. The concept of coopetition as a synergistic phenomenon has important implications for the nonprofit arts sector that extend beyond the individual paradoxical constructs of competition and cooperation. In a field that has historically stressed artistic and operational competitive advantage, but struggled with chronic funding and scarce resource issues, the assertion that the best strategy often involves cooperation with competitors and the potential to achieve results greater than the sum of inputs, with multiple winners, is a powerful one for nonprofit arts organizations.

This research has two primary components: (1) exploration, with an in-depth qualitative study, of the nature and extent of cooperation among competitors in the nonprofit arts arena, and (2) assessment, with a significant quantitative study, of coopetition using a relatively homogeneous segment of nonprofit arts organizations: symphony orchestras. Coopetition was evaluated in terms of two constructs: artistic coopetition and operational/marketing/fund development coopetition. Measures of coopetition included coopetition intensity, and range and volume of cooperative efforts. Consequences related to coopetition included perceived organizational financial performance and organizational effectiveness.

The qualitative study explored the nature of coopetition, components of the theoretical model, and related key variables in the context of nonprofit arts organizations. The sample for the study included eleven Executive Directors (or their equivalents) of a variety of types of nonprofit arts organizations located within the geographic area of Hampton Roads, Virginia, which includes 1.7 million people in nine cities and seven counties and comprises the $34^{\text {th }}$ largest Metropolitan Statistical Area (MSA) in the U.S. Individual structured, guided interviews were completed with the study participants, using a 21-item format developed to elicit feedback on concepts and related variables suggested by prior research. Finalization and operationalization of the model and component factors assessed in the quantitative study were based on the results of the qualitative study. Six latent constructs contained in the conceptual model of coopetition and its consequences were measured by 43 items in an 80-item questionnaire which was mailed to the executive directors of the entire population of 888 orchestras which were members of the League of American Orchestras. 266 of the 283 returned responses were complete and used for analysis, yielding an effective response rate of $30 \%$. The data was analyzed using AMOS structural equation modeling software. After revision of the model based on the results and theoretical support, confirmatory factor analysis and valuation of structural components of the model indicated support for all of the hypothesed relationships.

The results of both studies indicate that executive directors of non-profit arts organizations cooperate with their peers in varying degrees in multiple areas (operational, marketing, fund development, and artistic), with generally positive financial and organizational results. There is significant potential for these organizations to leverage potential benefits of cooperation, on a carefully-evaluated case-by-case basis, when analysis indicates that win-win, mutually beneficial opportunities exist.

References Available Upon Request 